\title{
The Heavy Burden of Proof for Ontological Naturalism
}

\author{
Georg Gasser \& Matthias Stefan \\ University of Innsbruck
}

\section{WHY NATURALISTS CANNOT DODGE ONTOLOGY}

$\mathrm{N}$ aturalism enjoys almost a status of orthodoxy among contemporary analytic philosophers. Unfortunately naturalism is not a clearly defined philosophical position. Rather it is comparable with a broad stream consisting of various philosophical approaches. It is not our aim to provide an elaborated definition of contemporary naturalism. Following Mike Rea's characterization (Rea 2002, 50-73) we consider naturalism to be a programmatic set of strategies to understand the world. Central to this programmatic set of strategies is to analyse and present the world by relying heavily on science (Forrest 1996, 89). Hence, naturalism implies the attitude to consider science (at least) as the primary source of reliable knowledge about reality. Science, according to naturalism, has shown to be the most successful strategy for understanding the structure of our world and its causal interaction (Löffler 1999, 36). This is the way we understand naturalism. Such a characterization is very vague. It leaves room for many different interpretations methodological, epistemological and ontological alike. In our paper we focus on ontological issues. We aim at exploring which ontological commitments come hand in hand with a naturalistic outlook on reality. This exploration presupposes that naturalism and ontological reflection are intertwined. An argument supporting this presupposition goes as follows:

Ontology is the philosophical discipline investigating the ultimate structures of reality. It aims at formulating what exists and what should be deemed as real or unreal. If it is true that naturalists claim that the methods of natural science exert a kind of hegemony over all strategies pursuing 
truth, then sciences are best in telling us what exists. Consequently ontology - according to naturalism - depends on what is recognised as real by sciences. A naturalistic minded philosopher, if asked what the ultimate structures of our world are, should consistently base his/her answer on current scientific research and the ontological commitments coming along with it. ${ }^{1}$

Many contemporary naturalists, however, refuse to pursue studies in ontology. They argue that naturalism should be interpreted neutrally from any ontological point of view. Ontological discussions tend to complicate - instead of enhancing - the interdisciplinary project between science, philosophy and common sense respectively (e.g. Tetens 2000, 287f.; Clayton 2004, 142). If naturalism leaves ontological discussions aside and concentrates on epistemology and methodology, for instance, it might support interdisciplinary projects between science and philosophy. It could start with concepts of folk psychology and take into account empirical investigations of cognitive science. In such a way naturalism might be helpful to analyse and better understand central concepts of cognitive science (Koppelberg 2000).

Whatever the specific merits of epistemological or methodological naturalism might be, they avoid the philosophical puzzles arising from ontological thought. Such or similar the argument goes against the view of taking ontological issues seriously within naturalism.

We concede that most scientists do not explicitly care for ontology. It is alien to scientific practice to spell out what a certain theory implies ontologically. This is rightly done. Scientists are not paid for doing ontology. However, we deem an ontologically neutral or abstinent naturalism unsatisfying from a philosophical point of view. If one accepts scientific realism and the thesis that explanatory concepts in science come along with ontological commitments, then a tension between different causal claims and various scientific explanations becomes a problem at some point. Psychology, for instance, makes causal claims about mental states and neuroscience makes causal claims about neurological facts.

Papineau 2001, for instance, aims at pointing out how modern physics led many philosophers to become ontological physicalists. Dupré 2004, 37ff., portrays a similar route from materialism over modern physics to physicalism. 
Now, if it is assumed (as most non-dualists would do) that mentality depends upon neuronal activity in the brain, then the question arises concerning the relation of these different causal claims. Are they just two different descriptions of the same reality? The decisive question is who or what is doing the causal work: Does mentality dispose of mental causal powers? Or is mentality only causally efficacious in virtue of its dependence upon neurological activity? This problem shows that it is not unusual that various scientific explanations and its corresponding ontological implications are in conflict with each other. There are causal entanglements between the various levels of reality investigated by different scientific disciplines. These causal entanglements raise all sorts of issues which have been dubbed "problem of causal competition", "problem of causal exclusion" or "problem of cross-level causation". These issues will have to be evaded or answered. Because it has proven to be difficult to provide a convincing way to evade the tensions between different causal stories at the various levels of reality, we assume that an ontological neutral position can only be provisional for naturalism: It might be useful to leave ontological implications out of account for specific aims of scientific research or philosophical reflection. However, if it is believed that scientific concepts and hypotheses refer to something real, then methodological and epistemological issues are closely intertwined with ontological assumptions. Ontological questions are neither external to scientific practice nor of no interest for science. Scientific theories make statements about entities being causally efficacious. By doing so, ontological questions are implicitly raised by scientific theories. If our argument is correct, naturalistic minded philosophers should regard it as a substantial topic of their research to work out which ultimate structures of reality we are reasonably enabled to accept according to naturalism. Ontology is not a marginal but a central issue for naturalism.

\section{NATURALISTS' COMPLAINT AND MEN OF STRAW}

After having argued for the importance of taking ontology seriously in naturalistic thought, in this section we discuss briefly which ontological options should be preferred over others. In surveying philosophical literature on naturalism we encounter again and again a complaint from the 
side of naturalists (see for instance Sukopp 2006, 28-33). Many naturalists complain they are attacked from two sides: First, they are attacked because naturalism is presented as being ultimately radically reductionist or eliminativist. Secondly, they are attacked because naturalism is presented in such a liberal way that almost everyone is willing to accept it.

According to the first line of attack naturalism coincides with reductive physicalism. Based upon contemporary physical theories it is claimed that our world contains only basic micro-physical entities. These entities together with fundamental physical laws are sufficient to account for all phenomena we encounter in our universe. Once the physical facts at the bottom level of reality and the laws holding them are fixed, all facts of our universe are fixed. There is nothing relevant above these fundamental physical facts. Such a position implies the (in principle) reduction of our macro-world to micro-physics, the (in principle) reduction of laws of special sciences to the fundamental laws of physics and the (in principle) reduction of 'non-physical phenomena' such as consciousness, subjectivity or intentionality to physical phenomena. In such a reductionist world ultimately only micro-physical entities and their causal interactions exist. For many people such an ontology has unpalatable consequences because the world we are familiar with is ontologically inferior or negligible. There are no physical facts above micro-physics, no causal powers above the powers of the ultimate constituent parts of reality. The world as we conceive it, the causal powers we ascribe to the objects of our mesocosmos, in short, our Lebenswelt, drains away after all. In the final analysis the ultimate level of reality - the level of micro-physics - is the only level which truly has to be taken seriously from an ontological (and maybe on the long run also from a scientific) point of view.

According to the second line of attack, ontological naturalism is so widely defined that nearly every ontological thesis is part of it. If only God, angels, immaterial substances or mythical creatures are excluded from a naturalistic ontology, then naturalism does not seem to offer any interesting ontological insights. Anyone who has not strong theistic, animistic or obscurantist tendencies would subscribe to such a version of ontological naturalism. A naturalism telling us that our world is material based, that it evolved over time in a continuous process, that complex systems consist of simpler parts, and that we do not have to postulate non- 
material entities for explaining our universe, is a rather unimpressive philosophical program. It might legitimately be asked whether such a view is still worth to be named naturalism (Stroud 2004, 34f., Keil and Schnädelbach 2000, 9f.).

Most naturalists consider the two options sketched above as mere men of straw which easily can be torn into pieces. This complaint from the naturalist's side implies that any serious analysis (and critique) of naturalism should look for positions being situated between a too strong reductionist physicalism and a too liberal naturalism. We take these complaints seriously. In the next section we aim at spelling out possible compromises between the two extremes.

\section{SCIENTISM AND ITS ONTOLOGICAL OPTIONS}

We presented naturalism as being committed to the attitude that science ultimately recognizes what is real and unreal. Any ontology faithful to this attitude has to be developed under the authoritative guidance of science. We label such an attitude 'scientism'. Kornblith gives a succinct expression of this view:

Current scientific theories are rich in their metaphysical implications. The task of the naturalist metaphysician, as I see it, is simply to draw out the metaphysical implications of contemporary science. A metaphysics which goes beyond the commitments of science is simply unsupported by the best available evidence. (Kornblith 1994, 40, our italics).

Kornblith's view is programmatic in character. Hence, let us ask: How shall an ontology be construed out of contemporary scientific theories? We suggest that first of all we have to clarify which sciences are to be accepted as providing relevant information for a naturalistic ontology. Second, we have to explain how the relevant sciences relate to each other. It is easy to see that these two problems are connected. A well-known example from the history of science helps to explicate this interconnection. The bonding problem in chemistry was a much debated topic at the edge of the $19^{\text {th }}$ century. As long as micro-explanations of chemical bonding were not at hand, chemical theories assumed fundamental chemical forces of chemical elements. After the development of quantum mechanics, the gap between 
chemistry and physics began to shrink. It was detected that quantum states and not some emergent chemical properties are the reason for chemical forces. Chemical bonding became explainable in terms of quantum mechanics. $^{2}$ The important point for our discussion is that in this case all relevant information is provided by physical theory. Physics tells us everything about the problem of chemical bonding. This scientific progress had influential consequences for ontology. Before quantum states were known, emergent chemical properties were assumed as being part of our world. After the discovery of quantum states the assumption of proper chemical properties became superfluous. As the example shows, it might be the case that within the disciplines, scientism considers as relevant for its ontological program, specific theories of a determinate discipline (e.g. chemistry) are reducible to more basic theories in another (e.g. physics). For a naturalist subscribing to scientism it is not only important to identify those sciences which provide relevant information for a naturalistic ontology; it is crucial to elucidate their interrelationship as well. We propose three solutions for achieving this aim:

(i) Scientism pursues a reductionist strategy. Scientism assumes that the entities of higher level sciences are reducible to micro-physical entities. Biological entities, for instance, ought to be reduced to chemical entities and these to physical ones. Scientism then turns into physicalism, as all higher level sciences are nothing more than special cases of (an assumed complete) science of physics.

(ii) Scientism becomes a kind of conciliable naturalism. Conciliable naturalism says we should accept everything as relevant that we think we need to make sense of and which we are convinced is part of our world (Stroud 2004, 33). Conciliable naturalism accepts the whole range from natural to social sciences, and humanities.

(iii) Scientism relies on some well established sciences, such as physics, chemistry and biology. We call this position

2 McLaughlin 1992 discusses these scientific discoveries at length and relates them directly to the rise and fall of British Emergentism. 
'naturalism of core sciences'. It might be claimed that this version of naturalism is some kind of a compromise: It avoids the openness of conciliable naturalism on the one hand without subscribing to a too strong reductionist version of physicalism on the other hand.

How shall we deal with the three options at hand? Position (i) is often considered problematic. It seems to coincide with the position identified above as our first man of straw because it claims that (micro-)physics alone provides the relevant information for any ontology. Position (ii) seems to be a non-starter due to its open-mindedness. Conciliable naturalism is not more than "a slogan on a banner raised to attract the admiration of those who agree that no supernatural agents are at work in the world." (Stroud 2004, 35) Conciliable naturalism is identifiable with the position identified above as our second man of straw.

The remaining candidate is position (iii). For our argument it is not of further importance whether 'naturalism of the core sciences' considers only physics, chemistry and biology as relevant sciences or whether the list can be extended ${ }^{3}$. Central for our argument is that a well-defined notion of sciences seems to be presupposed. Explicating the concept of science is a necessary precondition for being able to say which sciences take part in the ontological undertaking of naturalism. It is, however, anything but clear what natural sciences are. As long as this problem remains unsolved the problem of sciences' interdependency cannot be tackled either. Without a clear concept of science, scientism can hardly justify why it takes certain sciences seriously for ontology, whereas others are seen as less important. This gives rise to the impression that an envisaged science based ontology amounts to a mere matter of taste-the groundless capriciousness of certain people to favour certain disciplines over others.

3 Of course, the list cannot be extended arbitrarily. This extension has to be stopped at some point before turning this position into a form of conciliable naturalism. But this problem is of no further importance here. 
Naturalists have to answer the question about their concept of science:

Having declared that the methods of natural science provide the only avenue to truth, the naturalist should be prepared to say what these methods are, or which sciences qualify as 'natural sciences.' (Keil 2000, 148)

There are three possibilities to develop such a concept of science:

(a) Providing methodological criteria which separate sciences from non-sciences.

(b) Providing a list of acceptable sciences.

(c) Demonstrating the unity of science.

Let us discuss the three possibilities in turn.

(a) It is a fact that in scientific progress methods of science develop. Long established methods in scientific practice are factored out as not being scientific enough anymore whereas other methods become integral parts of current scientific practice. Standards what counts as scientific and what as unscientific change with the course of science's development. In short, the methods of science cannot be determined a priori. Our characterization of naturalism implies that naturalism finds its orientation within science and in this respect it is at science's mercy. As a consequence, naturalism cannot impose a priori methodological criteria on science. Otherwise naturalism is not a loyal companion of science anymore but sets itself up as judge over it. Such a move is inconsistent with naturalism's commitment to follow and cooperate with science. If this argument is sound, naturalism cannot develop criteria for distinguishing sciences from non-sciences because such criteria would determine a priori what has to count as science and what not.

(b) Providing a list of admissible sciences has also to be refused. It is impossible to provide a non-arbitrary list of accepted sciences without methodological criteria. If we look for methodological criteria, we are back at (a), which has been already ruled out as a possible solution to the problem at hand.

(c) Demonstrating the unity of science seems to be a philosophical project most evidence speaks against. We have little reason to believe in any kind of unity of science. If we look at science as practiced, then we are 
unable to notice any methods of investigation which are characteristic for all sciences. There are also naturalistic attempts to provide a unity of sciences in content, which assumes that all sciences investigate entities that are one and the same in nature. These entities might be, for instance, physical in nature, so that all sciences are united in having physical content. Such a move brings us, finally, to the doctrine of physicalism which we have discussed as a first possible interpretation of scientism. Whether this is a viable way we have to let others decide. Currently such attempts lack any convincing philosophical basis and empirical support. There are no signs of a realisation of the project of the unity of science in terms of method and content (Dupré 2004, 51).

Scientism seems to be incapable of giving an adequate concept of science. Without such a concept, however, it is impossible to construe an ontology out of contemporary scientific theories. And even if we assume, for the sake of argument, that scientism possesses such a concept of science, an abiding problem for a science-based ontology still remains, namely that of the interdependency of sciences. Most sciences imply 'local ontologies'. A local ontology is the ontology a scientific discipline (or even a specific theory within a discipline) uses explicitly or implicitly for its area of research. Biology, for instance, (to speak simplified) works among other ontological categories with three-dimensional objects, such as organisms for explaining biological phenomena. Many of these objects of biological research correspond to objects we are familiar with from common sense. Particle physics instead might carry out its research in a four dimensional time-space system with fields, atoms and electron clouds. It might not feel the urge to refer to three-dimensional objects familiar to us from everyday experience. ${ }^{4}$ It is of no further importance for our argumentation what entities exactly are assumed in different scientific areas. It suffices to point to the fact that different local ontologies in different sciences lead irreversibly to an unpleasant consequence: Various sciences use different ontological categories, while their interrelationship is everything but clear. Advocates of scientism have to explain how different

4 It should be noted that this assumed ontological framework for physics, which is already simplified, is not at all undisputed. Within physics itself are many sites of (epistemological and ontological) fracture (see Falkenburg 2006). 
ontological categories, drawn out of contemporary science, relate to each other. If a clarification of these relationships cannot be provided, the project of scientism is seriously threatened. It is as if we had many pieces of a puzzle and did not know how to put them together to a unified picture.

A naturalist might reply that a thoroughgoing science-based ontology is not available. There are gaps in a science-based ontology. As the various sciences are not united so the local ontologies are not related to them. These gaps have to be accepted as expressions of our ignorance within the project of a science-based ontology. All we have are small puzzles, but a great unifying picture is simply beyond our reach. We ought to live with a fragmented ontology of our reality.

We see the main problem of such a proposal in the acceptance of gaps. As argued before, scientism needs to draw a line between acceptable and unacceptable sciences for being able to construe its ontology. Often this line is drawn between natural sciences and other academic disciplines which have the mental or the social as their primary research object (Mellor/Crane 1995). Let us suppose there are reasonable grounds to draw the distinction at the intersection of those sciences concerned with the physical and those studying the assumed non-physical. If, for the sake of argument, we accept this distinction we should be prepared to answer the question why we are willing to tolerate gaps among the natural sciences and still adhere to the drawn distinction. Why should we consider a fragmentation between particle physics, atomic and molecular theory, biology, physiology, or neurology as less problematic than the gap between the physical and the mental? This assumption grounds on the presupposition of the unity of the accepted sciences. It is presupposed that one can smoothly go up the hierarchy of sciences from physics over chemistry and biology to neurobiology without any change in content. It is always the same realm that is investigated. The only problematic gap, then, is lurking between the physical and the mental. Implicitly it is presupposed that the mental stands alone in our physical world (Churchland 1981, 75). This presupposition, however, is by itself not justified, as the unity of science has to be provided first. And we saw already that the signs of a realisation of the project of the unity of science are currently few and far between. 
If scientism goes another route instead and accepts gaps for its ontological undertaking within sciences itself, as well as a further gap between so called hard and soft sciences, then a science based ontology does not have any reason to favour the subject matter of hard sciences over the one of soft sciences. Scientism, then, would accept a plurality of sciences as equally relevant for ontology. There would not be one ontology but many ontologies depending on the respective (scientific) perspective one takes up for getting an accurate account of the phenomena under investigation. It seems likely to us that such a view turns into liberal naturalism which has been ruled out as a non-starter at the very beginning of the discussion. What our discussion should have made clear is the following:

(i) If almost everything is assumed as being part of nature, then naturalism becomes so liberal that it turns into triviality.

(ii) There is no generally accepted concept of science which allows drawing a clear line between acceptable and nonacceptable sciences. Criteria to distinguish between relevant and irrelevant sciences seem to be difficult to obtain. Without such criteria, however, the entire project of a science-based ontology cannot be achieved. It remains unclear to which sciences ontology should refer.

(iii) Even if it could plausibly be argued which sciences a naturalistic minded philosopher should take into consideration for his/her ontological studies, the interrelationship between the accepted sciences and their assumed entities has still to be clarified.

Drawing out the ontological implications of contemporary science, as Kornblith demanded, has shown to be full of flaws. Scientism as a philosophical project seems to be a failure - at least from the perspective of its ontological implications. How shall we proceed then? We suggest returning to one option we presented at the beginning of our discussion: physicalism. It seems to be the only remaining option providing a solution for the problems of the notion of science and the interdependency between scientific disciplines. If this were true, naturalists should accept what they 
are generally loath to do: To argue that physicalism, and the reductionism coming along with it, is the most promising route for presenting a distinctive naturalistic ontology.

\section{ONTOLOGICAL PHYSICALISM}

How shall physicalism be characterized? We start with a list of core tenets physicalism $^{5}$ entails (see e.g. Pettit 1993, 213-223; Beckermann 2000, 128143; Kim 2005, 149f.):

(1) The world is constituted out of microphysical entities which physics is in the best position to identify. Every entity in the world is either a microphysical entity itself or constitutes of microphysical entities.

(2) Microphysical entities are subject to law-like regularities described by physics. Since microphysical entities constitute everything, macro-entities are subject to laws which are constituted by microphysical laws.

(3) Once microphysical entities and law-like regularities holding them are fixed, all facts are fixed-metaphysically speaking (Loewer 2001a, 39). This is implied by (i) and (ii).

(4) Higher level entities exist by being identical to or by supervening upon physical entities. This thesis itself remains tacit whether we can still be realistic about higher level entities (Kornblith 1994, 42; Loewer 2001a, 46; Hüttemann/Papineau 2005, 34).

5 Physicalism is an ambiguous term. Some philosophers call themselves physicalists but in fact they reject only the acceptance of non-material substances in our world. Such a version of physicalism is identifiable with what we call 'liberal or conciliable naturalism'. We think it is ill-founded to label such a view 'physicalism' as it creates more confusion than clarifications. Others, however, propose some constrained notion of physicalism, which we aim at defining in points (1) to (6). We leave it open which commitments the single philosophical tenets entail. The point is rather, that everyone accepting tenets (1) to (6) faces the problem we expose in what fallows. 
(5) Causation of non-fundamental entities exists supervening upon or depending on physical facts and laws. This thesis does not rule out that higher level causation exists as well.

(6) Physicalim's commitment to the thesis that higher level entities are sums of or supervenient upon physical entities leaves open whether higher level entities are only adequately studied and interpreted via a reductionist methodology and ontology.

Tenets (1) to (6) leave room for a variety of physicalistic positions. A certain prevalence for microphysical entities and the objects studied by physics can be noticed as general commitment of them all. But at this point physicalism is still open to various interpretations reductionist and nonreductionist alike.

Reductionists claim that all higher level entities are (in principle) reducible to physical ones. According to reductionism, higher level entities present no domain of their own but are reducible to and identical with entities in the physical realm. In a final analysis, all that exists are physical entities - whatever they may be - and sums of them.

Non-reductive physicalists reject a strong reading of (1) to (6). They accept the existence of higher level entities in a genuine sense as well. ${ }^{6}$ According to non-reductive physicalists there are facts in the world that simply cannot be stated or noticed in terms of lower level entities. It is the failure of reduction because of the incompleteness of lower level ontology that justifies the acceptance of irreducible higher level entities. These higher level entities are asymmetrically dependent on the physical level. This dependency-relation is mostly dubbed as supervenience relation. Basically it says: No changes at the higher levels without changes at the lower level. Two systems exemplifying exactly the same physical states exemplify the same higher level states as well, but not the other way around.

What should be noted at this point is that reductionists and nonreductionists share a common worry: To leave out important features of our world which we care about. If reductionists aim at reducing higher

${ }^{6}$ For a detailed version of non-reductive physicalism see e.g. Poland 1994. 
level entities to lower ones then they do so for being realists about higher level entities. By providing a reduction, higher level entities no longer 'hover over' the physical world but become a part of it. The existence and causal efficacy of higher level entities is thus guaranteed by reducing them. The worry of most reductionists is that entities which cannot be reduced will prove to be epiphenomenal or, even worse, unreal altogether (Kim 1995). Exactly the same worry drives non-reductionists as well. They hold, however, the opposite view of what counts as legitimizing higher level entities. For non-reductionists reduction amounts to elimination of higher level entities: If mental states are reducible to physical states, then there are only physical states. Mental states become superfluous, ontologically speaking. To protect the ontological status of higher level entities it has to be shown that they are indispensable and irreducible. Any ontology leaving them out or not granting them the full right to exist would be incomplete: Important parts of our world would be missing.

The reason we stress this common worry of reductive and non-reductive physicalists alike is to avoid a 'straw man argument' in the discussion. Often anti-naturalists argue that naturalists do not ascribe great importance to such crucial features of our self-conception as subjectivity or the firstperson-perspective. Such a reproach misses the mark. Many naturalists aim at naturalizing these features via reductionist strategies. Only few consider them as entirely eliminable or superfluous. Thus, reduction should not be confused with elimination (see Kim 2005, 160). Naturalization via reduction means to provide a home for ontologically disputable entities such as mental entities within an ontologically undisputed realm such as the physical.

Probably most philosophers fancying physicalism, subscribe to a version of non-reductive physicalism. According to them one can go up the hierarchy of levels and consider entities at higher levels as real without being forced to assume new kinds of obscure metaphysical ingredients like vital forces, entelechies or souls. Higher entities do not consist of physical parts and something non-physical. All the entities being there are "physical in nature". Being physical in nature, however, does not imply that higher level entities and their properties are reducible to the sums of physical particles and their properties. 
Thus, one might want to say that higher-level entities, such as human beings, are real - as real as the entities that compose them-and at the same time reject all sorts of vitalism or dualism. (Murphy 1999, 130)

Higher level entities supervene upon their physical basis but the ontological significance of these entities is acknowledged because a comprehensive reduction to their basis is excluded.

With the distinction of reductive and non-reductive physicalism in mind it is easier to notice the conflict between (1) to (6). The conflict is to be located between the ontological primacy of the physical level on the one hand and a realist understanding of higher level entities on the other hand. Perplexities arise when we ask how higher level entities ought to be characterized ontologically. The discussion should have made clear that non-reductive physicalists have to solve a major problem of their account: The assumed dependency of higher level entities on the physical oscillates between reductionism and breaking the seal of the physical domain: Either dependency and supervenience is defined in such a way that higher level entities are identical and consequently reducible to physical ones or dependency is so weakly defined that the higher level domain gets a life on its own (Kim 1995). Then it is hard to keep the higher level domain in check within a physicalist framework. The problem for non-reductive physicalism can be stated in the form of a dilemma which is similar to the one of scientism in general: Non-reductive physicalism aims at interpreting the world of our common sense realistically. For achieving this purpose it considers mere dependency or supervenience relations on the physical as sufficient. Thereby the physical level loses in importance and definiteness. Non-reductive physicalism runs the risk to burst the physical realm altogether and thus turning into a version of liberal naturalism. If, on the contrary, the domain of the physical is kept restrictive, then non-reductive physicalism seems to slide into reductive physicalism. In what follows, we present an argument that tightens this assumption.

\section{ONTOLOGICAL PHYSICALISM AND REDUCTIONISM}

In various articles Kim argued at length that non-reductive physicalism is an unstable house of cards. It is a promissory note between the poles of 
open mindedness and reductionist physicalism which has not been cashed out yet. Kim reminds non-reductive physicalists to be consequent:

[...] if you have already made your commitment to a version of physicalism worth the name, you must accept the reducibility of the psychological to the physical [...]. (Kim 1995, 134)

Kim's argument concerns not only the mental but can be generalized for all higher level entities since the mental is just one kind of higher level entity among others (Loewer 2001b; Sparber 2005; especially Kim 2005, 52-56).

Before focusing on Kim's argument itself, something needs to be said about its premises: It is crucial for the argument that physicalists subscribe to the principle of causal closure of the physical (CCP). CCP has been stated in different constructions (e.g. Papineau 1993, 16f. and 29-32; Armstrong 1995, 38; Papineau 2001; Kim 2005, 15f.). CCP says something like the following: "At every time at which a physical state has a cause, it has a fully sufficient physical cause" (Lowe 2000, 27). Every physical state $P$ which is caused at a certain time $t$ has as its cause a set of other physical states existing at this certain time $t$, such that: (i) each of these states is a cause of $P$ and (ii) together they are causally sufficient for $P$ (ibid.). Physicalists "worth the name" accept CCP equally. If CCP is rejected, various kinds of non-physical entities could be accepted as causes of physical states. One major problem with this assumption is that these entities are not accessible to physics. According to most physicalists CCP is a presupposition which is part of a reasonable interpretation of our physical theories about the world. Otherwise physics could not be applied to certain domains of our reality (e.g. Armstrong 1995, 38; Beckermann 2000).

Additionally physicalists accept a supervenience relation of higher level entities to lower level ones. The supervenience relation is supposed to grant that higher level entities are 'bound' to lower level ones. The assumption of identity of higher level phenomena to physical ones is perfectly compatible with the assumption of supervenience.

If these two premises are accepted, Kim's argument briefly goes as follows (Kim 1995, Kim 2005): For the easiness of illustration, we call any arbitrary higher order state $M_{n}$ and any arbitrary lower level state $P_{n}$ : First, higher order states are supervenient on lower level ones. If there are two 
arbitrary higher level states $M_{1}$ and $M_{2}$, then there must also be two lower level states $P_{1}$ and $P_{2} . P_{1}$ and $P_{2}$ are the supervenience bases of $M_{1}$ and $M_{2}$. Suppose now, that $M_{1}$ causes $M_{2}$. If this is assumed, $M_{1}$ would have to cause $P_{2}$ as well in virtue of which $M_{2}$ appears. However, because of the causal closure principle, $P_{2}$ must also be caused by $P_{1}$, while the appearance of $P_{2}$ allows $M_{2}$ to exist. As the domain of the physical is closed (according to the physicalist) $M_{1}$ cannot by itself cause $P_{2}$. Thus, $P_{1}$ must cause $P_{2}$. Therefore the causal chain from $P_{1}$ to $P_{2}$ and to the supervenience of $M_{2}$ is sufficient for $M_{2}$ to appear. Since a physicalist accepts the causal closure principle, the causal chain from $P_{1}$ to $P_{2}$ is not only sufficient but furthermore the only acceptable one for him. If $M_{1}$ really causes $M_{2}$, and the causal chain leading to $M_{2}$ starts with $M_{1}$ 's supervenience base $P_{1}$, then $M_{1}$ must be identical with $P_{1}$. Thus, taking higher level causation seriously within a physicalist ontological framework, this embraces the thesis that only reducible higher level entities possess causal efficacy. The main purpose of the argument is to show that the assumption of the supervenience relation together with CCP lead to a determinate ontological commitment. This commitment states that higher level phenomena make a difference only if-via the supervenience relation - they are identifiable and hereby reducible to physical states.

Such a conclusion follows if causal over-determination $\left(M_{1}\right.$ and $P_{1}$ each fully sufficiently cause $M_{2}$ at the same time $t$ ) on the one hand and partial causation $\left(M_{1}\right.$ and $P_{1}$ together partially cause $M_{2}$ at $\left.t\right)$ on the other hand are excluded. Assuming a (constant) causal over-determination would lead us to a highly fragmented understanding of reality because various causal histories for a single event would be equally true. Apart from this undesirable result there is no empirical evidence for it (for a further assessment of this assumption see Sparber 2005). Partial causation, on the contrary, is excluded by CCP itself, as it states that every physical event has a sufficient physical cause. Thus, a physicalist — by accepting CCP and some kind of supervenience relation-faces pressing ontological reasons for embracing as well the thesis that ontological relevant states at higher levels are identical and thereby reducible to the states of the bottom level of reality. CCP and supervenience seem to be intertwined insoluble with the ontological commitment that all facts are fixed on the bottom level of reality. 
What CCP does not rule out are epiphenomenal states. Epiphenomenal states are higher level states which are not reducible to physical ones but which are causally powerless. As such, epiphenomenal states remain outside the realm of the physical. Nevertheless they are often considered to be no serious threat to a physicalist framework as they are causally ineffective. ${ }^{7}$ It might, however, be asked whether epiphenomenalism truly can be dispatched so easily from physicalism. If epiphenomena are causally irrelevant, how can we know anything about them? As we have knowledge about them, they must somehow directly or indirectly affect us:

If a thing lacks any power, if it has no possible effects, then, although it may exist, we can never have any good reason to believe that it exists. (Armstrong 1995, 40)

Any good reason for assuming the existence of an entity is due to its causal efficacy, by whose virtue we get knowledge of it. So either we have a good reason for assuming the existence of an entity, but then we must accept that it affects us in some way and is no epiphenomenon anymore; or it is an epiphenomenon but then we can really have no good reason for assuming its existence. Epiphenomenalism seems to be a too cheap way out for physicalism. A thoroughly coherent form of physicalism is pushed towards complete reduction.

We do not want to dwell on this issue any longer because it launches a discussion on its own. The decisive point we wanted to raise is whether it can be shown that higher level phenomena are reducible to physical entities or not. If not, we have to assume the existence of irreducible higher level phenomena. Then, a thorough physicalist ontology is unable to capture certain features of our world. Physicalism as a comprehensive ontological program has failed. ${ }^{8}$ If it can be shown instead that no such irreducible phenomena exist, reductionism is on its move. It is our impression that many physicalists postpone the pressing answers how their

7 Kim for instance takes qualia as epiphenomenal states; see Kim 2005, 22-29, and 170-173.

8 An alternative possibility is simply to deny those entities which do not fit into a physicalist picture. Melnyk 2003, 42f., explicitly denies all entities that cannot be reduced. Whatever the merits of such a strategy are, Melnyk agrees with us that reductionism must be comprehensive and thorough. 
acceptance of CCP and/or their conception of supervenience are reconcilable with an ontologically realistic understanding of a layered model of reality. If our arguments are correct they pinpoint that a nonreductive physicalist faces unavoidably conflicts between the assumptions of different levels of reality: Questions concerning the causal closure of the physical domain and the ontological overlapping or competition of higher and lower level entities call for an answer.

At this point a proponent of the reductionist program might refer to science's future success of accomplishing complete reduction. Although we are currently still remote from such a state in science's development, a glance at the history of science sheds hope: Successful programs of reduction already have been carried out and further ones will follow. Thus, it is legitimate to suppose that new forms of reduction will once be as successful as it already has been proven to be in other realms of science. ${ }^{9}$

We do not think that referring to successful examples in the history of science is really a convincing argument for a general reductionist outlook. There are many phenomena tenaciously resisting reduction as contemporary debates in philosophy of mind or philosophy of nature show. Nor is it satisfying to talk about 'reduction in principle' or 'reduction being possible in the long run of science'. To refer to a future point in science's progress (when the program of reduction finally will be carried out) runs a risk of becoming a mere strategy of immunisation in the face of unsuccessful attempts of reduction. The same holds for the claim that reduction is possible in principle, but cannot be executed in practice because the entities which are to be reduced are too complex. The physicist Falkenburg plausibly demands that successful reductionism has to be carried out in a double way: It needs to analyse higher level entities into physical ones (top down reduction) on the one hand and it has to be shown how higher level phenomena result from its physical constituents (bottom up reduction) on the other hand (Falkenburg 2006, 61-68).

9 See, for instance, Kim 2005, 68, citing McLaughlin 1992. 


\section{CONCLUSION}

Naturalism is a very popular philosophical position. We share its underlying conviction that modern sciences help us to see many things clearer, also in the field of ontology. But the problem is that there is no direct way from the subject matter of sciences to ontology. The aim of our paper was not to present new arguments in favour of naturalism or against it. Its aim was to map the landscape of the current discussion of ontological naturalism and to portray the ways a naturalist might want to go within it.

We pointed out that naturalism has no clear concept of science. Therefore it is hard to tell from which sciences naturalists should or could derive their ontology. Even if a list of acceptable sciences were provided, serious questions would remain: How do the ontological implications of the accepted sciences relate to each other? And do some sciences have a higher priority in determining ontology than others?

According to our analysis the most promising way for naturalists to elaborate a science-based, uniform, and coherent ontology is physicalism. Many of the contemporary physicalistic positions, however, accept CCP and supervenience - the core assumptions of physicalism-on the one hand but reject reductionism on the other hand. We do not see how this wish-list of non-reductive physicalism can be brought together consistently. A physicalist is committed to reductionism, as Loewer ${ }^{10}$ unwittingly summarizes our conclusion:

[...] philosophers true to their physicalism will have to swallow reductionism.

Those who find reductionism impossible to swallow will have to find a way of living without physicalism. (Loewer 2001b, 315)

Some naturalists might have the impression to face another 'straw man argument' of naturalism being fought here. But we aimed at interpreting naturalism benevolently. We neither rejected its allegiance to science nor did we claim naturalism to be a failure as a philosophical program. We rather wanted to press the naturalist to consider more carefully the

${ }^{10}$ Loewer himself wants to avoid this conclusion-against his line of argument see Sparber 2005. 
ontological commitments she enters by taking science as authoritative guidance for philosophy in general and ontology in particular.

We do not know where science will lead us and whether naturalism will have a better standing in the future. Contemporary naturalism, however, carries a heavy burden: If it wants to be successful, it either has to show how reductionism is possible, or it has to point out convincing ways for manoeuvring between reductionism and too liberal versions of naturalism.

\section{REFERENCES}

Armstrong, D. 1995: "Naturalism, Materialism, and First Philosophy." In: Moser, P. K. and Trout J. D. (eds.) Contemporary Materialism. New York: Routledge, 35-47.

Beckermann, A. 2000: "Ein Argument für den Physikalismus." In. Keil, G. und Schnädelbach, H. (eds.) Naturalismus. Frankfurt am Main: Suhrkamp, 128-143.

Clayton, P. 2004: Mind and Emergence. From Quantum to Consciousness. Oxford: Oxford University Press.

Crane, T. and Mellor, H. 1995: "There is no question of physicalism." In: Moser, P. K. and Trout J. D. (eds.) Contemporary Materialism. New York: Routledge, 65-89.

Dupré, J. 2004: “The Miracle of Monism.” In: De Caro, M. and Macarthur, D. (eds.) Naturalism in Question. Cambridge, MA: Harvard University Press, 36-58.

Falkenburg B. 2006: "Was heißt es, determiniert zu sein? Grenzen naturwissenschaftlicher Erklärung." In: Sturma, D. (ed.) Philosophie und Neurowissenschaften. Frankfurt am Main: Suhrkamp, 43-74.

Forrest, P. 1996: God without the supernatural: A defense of scientific theism. Ithaca: Cornell University Press.

Hüttemann, A. and Papineau, D. 2005: "Physicalism decomposed." Analysis 65, 33-39.

Keil, G. 2000: "Naturalism in the philosophy of mind - and what is wrong with it." In: Nannini, S. and Sandkühler, H. J. (eds.) Naturalism in the Cognitive Sciences and the Philosophy of Mind. Frankfurt am Main: Peter Lang, 145-155. 
Keil, G. and Schnädelbach, H. 2000: "Naturalismus." In: Keil, G. and Schnädelbach, H. (eds.) Naturalismus. Philosophische Beiträge. Frankfurt am Main:Suhrkamp, 7-45.

Kim, J. 1995: "The Myth of Nonreductive Materialism.” In: Moser, P. K. and Trout J. D. (eds.) Contemporary Materialism. New York: Routledge, 133-149.

Kim, J. 2005: Physicalism or something near enough. Princeton, NJ: Princeton University Press.

Koppelberg, D. 2000: "Forms of Naturalism in the Philosophy of Mind."

In: Nannini, S. and Sandkühler, H. J. (eds.) Naturalism in the

Cognitive Sciences and the Philosophy of Mind. Frankfurt am Main: Suhrkamp, 11-29.

Kornblith, H. 1994: "Naturalism: Both Metaphysical and Epistemological." Midwest Studies in Philosophy 29, 39-52.

Loewer, B. 2001a: "From Physics to Physicalism." In: Loewer, B. and Gillet, C. (eds.) Physicalism and its Discontents. Cambridge: Cambridge University Press, 37-56.

Loewer, B. 2001b: "Review of Jaegwon Kim, Mind in a Physical World. An essay on the mind-body problem and mental causation." Journal of Philosophy 98, 315-324.

Löffler, W. 1999: "Naturalisierungsprogramme und ihre methodologischen Grenzen." In: Quitterer, J. and Runggaldier, E. (eds.) Der neue Naturalismus. Köln: Kohlhammer, 30-76.

Lowe, J. E. 2000: Introduction to the philosophy of mind. Cambridge: Cambridge University Press.

McLaughlin, B. 1992: "The Rise and Fall of British Emergentism." In: Beckermann, A.; Flohr, H. and Kim, J. (eds.) Emergence or reduction?: Essays on the prospects of Nonreductive Physicalism. Berlin, New York: De Gruyter, 49-93.

Melnyk, A. 2003: A physicalist manifesto: thoroughly modern materialism. Cambridge: Cambridge University Press.

Murphy, N. 1999: "Nonreductive Physicalism. Philosophical Issues." In: Brown, W. S., Murphy, N. and Malony, N. (eds.) Whatever Happened to the Soul? Scientific and Theological Portraits of Human Nature. Minneapolis, MN: Fortress Press, 127-148. 
Papineau, D. 1993: Philosophical Naturalism. Oxford: Oxford University Press.

Papineau, D. 2001: "The Rise of Physicalism." In: Loewer, B. and Gillet, C. (eds.) Physicalism and its discontents. Cambridge: Cambridge University Press, 3-36.

Pettit, P. 1993: "A definition of Physicalism." Analysis 53, 213-223.

Poland, J. 1994: Physicalism. The Philosophical Foundations. Oxford: Clarendon Press.

Rea, M. 2002: World Without Design: The Ontological Consequences of Naturalism. Oxford: Oxford University Press.

Sparber, G. 2005: "Counterfactual overdetermination vs. the causal exclusion problem." History and Philosophy of the Life Sciences 27, 479-490.

Stroud, B. 2004: "The Charm of Naturalism." In: De Caro, M. and Macarthur, D. (eds.) Naturalism in Question. Cambridge, MA: Harvard University Press, 21-35.

Sukopp T. 2006: Naturalismus. Kritik und Verteidigung erkenntnistheoretischer Positionen. Frankfurt am Main: Ontos.

Tetens, H. 2000: "Der gemäßigte Naturalismus der Wissenschaften." In: Keil, G. and Schnädelbach, H. (eds.) Naturalismus. Philosophische Beiträge. Frankfurt am Main: Suhrkamp, 273-288. 